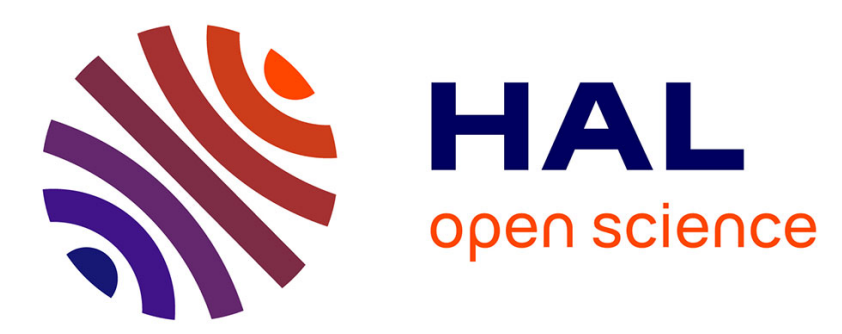

\title{
A kinematic and dynamic comparison of surface and underwater displacement in high level monofin swimming
}

\author{
Guillaume Nicolas, Benoit Bideau
}

\section{To cite this version:}

Guillaume Nicolas, Benoit Bideau. A kinematic and dynamic comparison of surface and underwater displacement in high level monofin swimming. Human Movement Science, 2009, 28 (4), pp.480. 10.1016/j.humov.2009.02.004 . hal-00557313

\section{HAL Id: hal-00557313 https://hal.science/hal-00557313}

Submitted on 19 Jan 2011

HAL is a multi-disciplinary open access archive for the deposit and dissemination of scientific research documents, whether they are published or not. The documents may come from teaching and research institutions in France or abroad, or from public or private research centers.
L'archive ouverte pluridisciplinaire HAL, est destinée au dépôt et à la diffusion de documents scientifiques de niveau recherche, publiés ou non, émanant des établissements d'enseignement et de recherche français ou étrangers, des laboratoires publics ou privés. 


\section{Accepted Manuscript}

A kinematic and dynamic comparison of surface and underwater displacement in high level monofin swimming

Guillaume Nicolas, Benoit Bideau

PII:

S0167-9457(09)00026-8

DOI:

10.1016/j.humov.2009.02.004

Reference:

HUMOV 1141

To appear in:

Human Movement Science

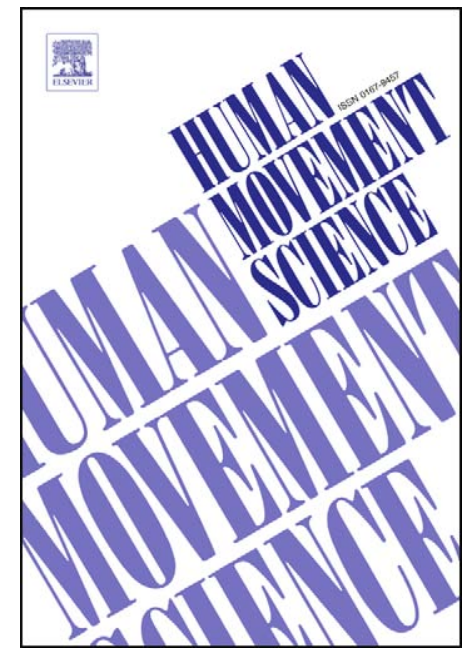

Please cite this article as: Nicolas, G., Bideau, B., A kinematic and dynamic comparison of surface and underwater displacement in high level monofin swimming, Human Movement Science (2009), doi: 10.1016/j.humov. 2009.02.004

This is a PDF file of an unedited manuscript that has been accepted for publication. As a service to our customers we are providing this early version of the manuscript. The manuscript will undergo copyediting, typesetting, and review of the resulting proof before it is published in its final form. Please note that during the production process errors may be discovered which could affect the content, and all legal disclaimers that apply to the journal pertain. 
18 Corresponding author:

19 Guillaume NICOLAS,

20 Phone: 02.99.14.17.75

21 Fax: 02.99.14.17.74

22 e-mail : guillaume.nicolas@uhb.fr

\section{Guillaume NICOLAS and Benoit BIDEAU}

Laboratoire M2S «Mouvement, Sport Santé » (Physiologie et Biomécanique)

Université Rennes 2 - ENS Cachan

Avenue Charles Tillon 35044 Rennes, France 


\section{Abstract}

Fin-swimming performance can be divided into underwater and surface water races. World records are about $10 \%$ faster for underwater swimming vs. surface swimming, but little is known about the advantage of underwater swimming for monofin swimming. Some authors reported that the air-water interface influences the kinematics and leads to a narrow vertical amplitude of the fin. On the one hand, surface swimming is expected to affect drag parameters (cross-sectional area (S) and active drag (AD)) when compared to underwater swimming. On the other hand, the surface swimming technique may also affect efficiency $\left(\eta_{F}\right)$. The aim of this study is therefore to evaluate and compare drag parameters and efficiency during underwater and surface swimming. To this end, 12 international level monofin swimmers were measured during both underwater and surface swimming. Kinematic parameters (both dimensional and non-dimensional), $\eta_{\mathrm{F}}$ (calculated according to the Elongated-Body Theory), and AD (computed with Velocity Perturbation Method) were calculated for an underwater and a surface fin-swimming trial, performed at maximal speed. As expected, results showed significantly lower velocities during surface swimming vs. underwater $\left(\overline{\mathrm{V}_{1, \text { under }}}=2.5 \mathrm{~m} \cdot \mathrm{s}^{-1} \mathrm{vs} . \overline{\mathrm{V}_{1, \text { surf }}}=2.36 \mathrm{~m} \cdot \mathrm{s}^{-1}, p<.01\right)$. Velocities during underwater and surface swimming were strongly correlated $(r=.97, p<.01)$. Underwater swimming was also associated with higher vertical amplitudes of the fin compared to surface swimming $\left(\overline{A_{\text {under }}}=0.55 \mathrm{~m}\right.$ vs. $\left.\overline{\mathrm{A}_{\text {surf }}}=0.46 \mathrm{~m}, p<.01\right)$. Length-specific amplitudes $\left(\mathrm{A}_{\text {under }} / \mathrm{L}_{\mathrm{b}}\right)$ were in the order of $20 \%$ during underwater swimming as for undulating fish, and significantly higher than during surface swimming $\left(\mathrm{A}_{\text {surf }} / \mathrm{L}_{\mathrm{b}}=17 \%, p<.01\right)$. Efficiency for surface swimming was about $6 \%$ lower than for underwater swimming $\left(\overline{\eta_{\mathrm{F}, \text { under }}}=0.79\right.$ vs. $\left.\overline{\eta_{\mathrm{F}, \text { surf }}}=0.74, p<.01\right)$. This decrease could be associated with an increase in swimming frequency for surface swimming $\left(\overline{\mathrm{f}}_{\text {surf }}=2.15 \mathrm{~Hz}\right.$ vs. $\left.\overline{\mathrm{f}}_{\text {under }}=2.08 \mathrm{~Hz}, p<.01\right)$. Active drag during surface swimming was about $7 \%$ higher than for underwater swimming $\left(\overline{\mathrm{AD}_{\text {under }}}=78.9 \mathrm{~N}\right.$ vs. $\left.\overline{\mathrm{AD}_{\text {surf }}}=84.7 \mathrm{~N}, p<.01\right)$. A significantly smaller cross-sectional area for surface swimming $\left(\overline{\mathrm{S}_{\text {under }}}=\right.$ $0.053 \mathrm{~m}^{2}$ vs. $\left.\overline{\mathrm{S}_{\text {surf }}}=0.044 \mathrm{~m}^{2}, p<.01\right)$ and higher drag coefficient for surface swimming $\left(\overline{\mathrm{C}_{\mathrm{d} \text {,under }}}=0.47\right.$ vs. $\left.\overline{\mathrm{C}_{\mathrm{d}, \text { surf }}}=0.69, p<.01\right)$ were measured. Finally, correlation between cross-sectional area and vertical 
1 amplitude of the fin was reported for both underwater and surface swimming. These results suggest that

2 the performance improvement during underwater swimming is not only linked to a wave drag reduction

3 effect but also to a specific swimming technique due to the free surface.

4

5 Key words: monofin swimming, active drag, Froude efficiency, swimming depth, biomechanics 


\section{Introduction}

Fin-swimming trials can be divided into two main categories. The first is displacement at the water surface. The second is the displacement underwater using two kinds of techniques: apnea and immersion with air bottles. The world records for both categories show that the mean speed is about $10 \%$ faster for underwater swimming than for surface swimming (Table 1).

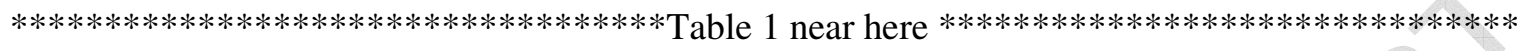

Table 1. World records in monofin swimming (updated on $20^{\text {th }}$ of May 2008) for males and females.

A first approach to analyze the fin-swimmer's performance is to determine his or her kinematic characteristics. Many authors have studied parameters as linear and angular instantaneous speeds, be it for the whole body (Gautier, Baly, Zanone, \& Watier, 2004; Szilagyi, Kocsis, Thukral, Lelovics, \& Barabas, 1999) or the lower extremities (Luk, Hong, Chu, \& Li, 1999). Such an analysis can be useful to identify decisive criteria for improving performance in specific events (e.g., turn technique) (Rejman \& Borowska, 2008). To provide new insights into undulatory swimming, some authors have also compared cetaceans and human hydrodynamics (Arellano, Pardillo, \& Gavilán, 2002; Nicolas, Bideau, Colobert, \& Berton, 2007; Ungerechts, 1983; Ungerechts, Daly, \& Zhu, 1998; van Oossanen \& Oosterveld, 1989; von Loebbecke, Mittal, Fish, \& Mark, 2009).

In order to establish a causal link between the observed performance and propelling aspects, a second approach can be considered from a dynamic point of view. The dynamic understanding of finswimming motion has been introduced by Rejman (1999), using strain gauges placed on both sides of the fin. However, to date no comparison has been made between surface and underwater movement using this method.

Only a few studies focused on the comparison of underwater and surface monofin swimming technique. They have generally been limited to kinematic parameters which are not sufficient to understand the adjustments between these two kinds of displacement. Indeed, in underwater displacement, the vertical amplitude of the trailing edge is shown to be higher than in surface (Luk et al., 1999; Szilagyi, 


(6)

Kocsis, Thukral, Lelovics, \& Barabas, 1999). However this result affects the swimming mechanics and may particularly have an effect on drag parameters.

For swimming near the water surface at a constant speed, three drag components can be distinguished: pressure or form drag $\left(D_{p}\right)$, friction drag $\left(D_{d}\right)$, and wave drag $\left(D_{w}\right)$ (Vogel, 1994). Hence total drag D equals (Eq. 1):

$$
\mathrm{D}=\mathrm{D}_{\mathrm{f}}+\mathrm{D}_{\mathrm{p}}+\mathrm{D}_{\mathrm{w}}
$$

Friction drag results from viscous shearing stresses in the boundary layer applied tangent to the wetted surface of the swimmer's body. The magnitude of friction drag depends on the wetted surface area of the body and flow conditions within the boundary layer (Vogel, 1994).

Pressure drag is caused by boundary layer separation. When swimming, the fluid layers are indeed deflected around the body. The boundary layers of fluid follow the contour of the body until the flow is either greatly slowed due to a pressure increase or accelerated due to a pressure decrease. At this event, the flow reverses and may roll up into distinct eddies (vortices). A pressure differential consequently arises between the front and the rear of the swimmer, which results in pressure drag according to (Eq. 2):

$$
D_{p}=\frac{1}{2} \rho \cdot S \cdot C_{f} \cdot V^{2}
$$

where $\rho$ is the density of the water $\left(1000 \mathrm{~kg} \cdot \mathrm{m}^{-3}\right), S$ is the cross-sectional area of the swimmer $\left(\mathrm{m}^{2}\right)$, and $\mathrm{C}_{\mathrm{f}}$ is a dimensionless form drag coefficient representing the streamlined shape and position of the swimmer. This component dominates at high Reynold's numbers, and is determined mainly by cross-sectional area (Clarys, 1979).

For swimming near the water surface, a third component of the total resistance is due to the wave drag. The mechanism behind this component is a transfer from kinetic energy of the swimmer to potential energy in the formation of waves. With increasing velocity, both the wave-length (the crest to crest distance) and the wave amplitude increase. At a certain speed, the wave-length will equal the "water-line length" of the swimmer. This swimming speed is called the "hull speed" (Toussaint \& Truijens, 2005; Vogel, 1994). Wave drag depends mainly on the swimmer's velocity, body shape, and movements in proximity to the water surface. It is considered to increase with the velocity cubed (Vogel, 1994). 
The contribution of each drag component to total drag depends on swimming speed. At high swimming speeds (particularly in monofin swimming), the contribution of wave drag may become more significant. The most common strategy to avoid the influence of wave-making resistance is to swim below the water surface (Toussaint, Roos, \& Kolmogorov, 2002). However, the optimal depth for a reduced drag remains difficult to evaluate. Most drag measurements have been obtained from towed bodies in a prone streamlined position (Clarys, 1979; Lyttle, Blanksby, Elliott, \& Lloyd, 1998; Vennell, Pease, \& Wilson, 2006). These studies generally reported a clear advantage of swimming underwater, with a decrease up to 2.4 times the drag when fully immersed (Vennell et al., 2006). Although this approach is very important to evaluate gliding technique, it is not possible to apply it to active swimming, particularly for undulatory swimmming for which unsteady effects may play a crucial role (Ungerechts et al., 1998). Lyttle, Blanksby, Elliott, and Lloyd (2000) were the first to examine active drag experienced during underwater kicking. Using a mechanical winch system, they were able to measure net force (i.e., total propulsive force minus the active drag force created during the kicking action) during towed swimming at $0.5 \mathrm{~m}$ depth, using dolphin or freestyle kicking style. Trends in the data indicated that the prone dolphin kick consistently produced lower net forces than the freestyle and lateral dolphin kick. However, the operating principle (towed swimmer) does not allow evaluating the swimmer in a manner close to reality. More globally, results of experimental studies on the magnitude of drag on and under the water surface still remain controversial because of the difference in design of towing devices and procedures (subject posture, depth of towing).

Many former studies considered that a swimmer may only improve performance by reducing the drag forces or by increasing the propulsive forces. However, to generate a propulsive force, the swimmer accelerates a mass of water, which acquires kinetic energy (Alexander, 1977). Hence, only a part of the total mechanical power output $\left(\mathrm{P}_{0}\right)$ is used beneficially to overcome body drag $\left(\mathrm{P}_{\mathrm{d}}\right)$, the other part being dissipated giving water un-useful kinetic energy because of the propulsion mechanism $\left(\mathrm{P}_{\mathrm{k}}\right)$. The ratio of the useful power $\left(\mathrm{P}_{\mathrm{d}}\right)$ to the total power output $\left(\mathrm{P}_{0}=\mathrm{P}_{\mathrm{d}}+\mathrm{P}_{\mathrm{k}}\right)$ is defined as the Froude efficiency (Lighthill, 1975) (Eq. 3): 
1

$$
\eta_{F}=\frac{P d}{P d+P k}
$$

From this equation, it is apparent that swimming performance depends not only on a high $\mathrm{P}_{0}$ but also on a high $\eta_{\mathrm{F}} ; \eta_{\mathrm{F}}=1$ means that the total power is equal to the thrust power, and $\eta_{\mathrm{F}}<1$ means that some of the total power is lost in imparting kinetic energy to the pushed-away water mass. The use of twin fins is clearly revealed to increase Froude efficiency by about 15 to $20 \%$ compared to bare feet: for leg kick $\left(\eta_{\mathrm{F}}=.61\right.$ without fins and $\eta_{\mathrm{F}}=.7$ with fins $)$ and in front-crawl $\left(\eta_{\mathrm{F}}=.42\right.$ without fins and $\eta_{\mathrm{F}}=.5$ with fins) (e.g., Zamparo, Capelli, Cautero, \& Di Nino, 2000; Zamparo, Pendergast, Mollendorf, Termin, \& Minetti, 2005). Monofins lead to a further increase in $\eta_{F}$ (up to .82) due to their larger propelling surface (Nicolas et al., 2007; Zamparo, Pendergast, Termin, \& Minetti, 2005). However other factors such as physical characteristics of fins, swimming speed, and level of expertise are also known to affect swimming efficiency (Nicolas et al., 2007; Zamparo et al., 2000; Zamparo, Pendergast, Termin et al., 2005). It might be questioned whether swimming depth also influences efficiency.

For a standardized swimming depth at $1 \mathrm{~m}$ under the surface, Nicolas et al. (2007) studied the adjustments between Strouhal number, active drag, and efficiency for high level monofin swimming. Results showed that active drag was increased with vertical motion of the fin, which increased crosssectional area. More generally, the fastest fin-swimmers had the lowest Strouhal numbers, lowest active drag and highest efficiencies, which suggested that increasing efficiency and reducing drag improves underwater performance at maximal speed.

In contrast, surface swimming is known to generate lower velocities than below surface. The airwater interface affects kinematics which leads to a narrow vertical amplitude of the fin (Szilagyi et al., 1999). On the one hand, this result is expected to affect drag parameters (cross-sectional area and active drag) when compared to underwater swimming, but no study reported the effect of this assessment. On the other hand, the surface swimming technique may also affect efficiency. The aim of this study is therefore to evaluate and compare drag parameters (cross-sectional area and active drag) and efficiency during surface and underwater swimming. This comparison between these two kinds of trials must reveal whether or not a specific adjustement occurs for surface displacement as a result of the free surface. 
2

3

\section{Methods}

To identify kinematic and dynamic parameters for underwater and surface displacement, we have introduced the below protocol. All participants were informed about the methods and aims of the study and gave their written informed consent prior to participation.

\subsection{Experimental procedure}

Twelve monofin swimmers, all members of the French National Team, were evaluated. All participants competed in many World Championships and four of them were medalists. Each participant first performed two underwater trials $(25 \mathrm{~m})$ at maximum speed: one swimming "free" and one swimming with an added drag. The same two trials were repeated when swimming at the surface. The following conditions applied:

- For surface swimming: the starting underwater phase was reduced to $5 \mathrm{~m}$ and was not taken into account in the experiment.

- For underwater swimming: given the possible effect of depth on wave drag (Vennell et al., 2006), the fin-swimmers were instructed to perform the trials at a depth of $1.0 \mathrm{~m}$. This could be accomplished after a period of familiarization and training. However, to ensure a constant depth, a two-step process was required. First, marks were set on the calibration frame close to the swimmer in order to help him keeping his depth as constant as possible. Then, an experimenter placed behind an underwater window visually validated (or not) the trial. Finally, a post-process enabled to precisely calculate the depth as the mean value (computed from three swimming cycles) of the vertical oscillations of the center of mass of the swimmer. During off-line processing of the data, all trials with a standard deviation (SD) on depth higher than $10 \%$ were rejected.

For both swimming conditions (i.e., underwater vs. surface), only the trial without the added load was considered in the kinematic analysis. The second trial was used only for the computation of active drag. 
Black tape markers were applied on selected anatomical landmarks to facilitate the digitizing process (see Fig. 1).

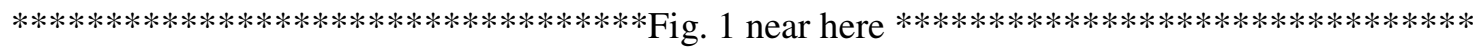

Fig. 1. Selected anatomical landmarks for video analysis.

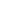

A side view of the monofin swimmer motion was video recorded using a $50-\mathrm{Hz}$ digital camcorder placed in a watertight box (Sony Handycam Vision, VX-2000E) (see Fig. 2). This camcorder was located at a distance of $7.5 \mathrm{~m}$ from the swimming trajectory and at a depth of $0.5 \mathrm{~m}$. A 16-point calibration frame $(4.8 \mathrm{~m} \times 2.1 \mathrm{~m} \times 1.6 \mathrm{~m})$ was initially placed in the swimming area for accurate calibration of the $3 \mathrm{D}$ space. The video recording was made at a distance of $10 \mathrm{~m}$ away from the initial impulse wall, to ensure that the velocity was obtained only from body self-propulsion. Another camcorder was placed in the frontal plane (at a distance of $25 \mathrm{~m}$ from the swimming pool board) to evaluate cross-sectional area. The underwater video frames were then manually digitized using a software package (SkillSpector v1.2, USA). A two-dimensional Linear Transform (2D-DLT) (Abdel Aziz \& Karara, 1971) was finally performed to determine all kinematic parameters.

*****************************Fig. 2 near here $* * * * * * * * * * * * * * * * * * * * * * * * * * * * * * * * * * * * * *$

Fig. 2. Monofin swimmer at a depth of $1.0 \mathrm{~m}$.

\subsection{Anthropometric and kinematic parameters}

For each participant, the following anthropometric and (dimensional) kinematic parameters were measured: body mass $(\mathrm{M})$, standing height $(\mathrm{H})$, body length $\left(\mathrm{L}_{\mathrm{b}}\right)$, kick frequency (f), kick amplitude (A), and mean swimming speed $\left(\mathrm{V}_{1}\right)$ (see Table 2$)$.

The standing height was measured in normal standing posture as the distance between the ground and the top of the head. Body length was defined as the posture with arms extended above the head (see Fig. 1) added to the fin length used by each swimmer. $\mathrm{L}_{\mathrm{b}}$ was estimated from digitized sequences as the mean distance between finger tip and trailing edge of the fin during one swimming cycle. The kick 
amplitude A was measured as the fin-beat peak-to-peak amplitude, i.e., the distance between the maximum and minimum vertical displacements of the fin's trailing edge. The frequency $f$ was defined by the ratio between the frame rate and the number of frames to complete one kick cycle. The velocity $U$ was determined by dividing the body length $\mathrm{L}_{\mathrm{b}}$ by the time elapsed between the fingertips and the toes passing the same reference mark (i.e., the time taken for the swimmer to traverse one body length). Because of differences in size between the swimmers, and in order to provide comparison to values recorded in some aquatic animals, we finally estimated the length-specific parameters for each trial: kick amplitude relative to body length percentage $A / L_{b}$, and specific (normalized) velocity $V_{1} / L_{b}$.

\subsection{Froude efficiency}

According to the Elongated-Body Theory (Lighthill, 1975), the Froude efficiency $\left(\eta_{\mathrm{F}}\right)$ of the undulatory movement of a slender fish can be computed according to (Eq. 4)

$$
\eta_{F}=\frac{\left(c+V_{1}\right)}{2 c}(4)
$$

where $c$ is the velocity of the progressing undulatory wave $\left(\mathrm{m} \cdot \mathrm{s}^{-1}\right)$. Waves of bending similar to the ones described for slender fish were reported for butterfly swimming (Ungerechts et al., 1998), twin finswimming (Zamparo, Pendergast, Termin, \& Minetti, 2002), and monofin swimming (Gautier et al., 2004; Szilagyi et al., 1999; Zamparo, Pendergast, Termin et al., 2005). In order to produce effective propulsion, $\eta_{\mathrm{F}}$ must lie between .5 and 1.0: the speed of the backward bending wave should be higher than the average forward speed of the swimmer. Wave speed $(c)$ was measured as indicated by Ungerechts (1983) and Zamparo et al. (2002) from the 2D coordinates of the hip, knee, and ankle joints. Each coordinate reaches its maximum displacement with a phase shift represented by a time lag $(\Delta t)$. The distance between the anatomical landmarks $\Delta \mathrm{l}_{\mathrm{T}}$ (the thigh length) and $\Delta \mathrm{l}_{\mathrm{S}}$ (the shank length) divided by the corresponding time lag between the waves maxima gives the velocity of the bending wave along the body $\left(\mathrm{c}=\Delta \mathrm{l}_{\mathrm{T}} / \Delta \mathrm{t}_{\mathrm{T}} ; \mathrm{c}=\Delta \mathrm{l}_{\mathrm{S}} / \Delta \mathrm{t}_{\mathrm{S}}\right)$. The Froude efficiency was finally calculated according to Eq. (4).

\subsection{Active drag}


At the same time, AD was computed with the ADES (Active Drag Evaluation System) (Bideau et al., 2003), based on Velocity Perturbation Method (VPM) (Kolmogorov \& Duplisheva, 1992). In the VPM, the swimmer needs to carry out two swimming trials at maximum speed, with and without a hydrodynamic body (HB). In both swims the power output to overcome drag is considered maximal and constant (Eq 5):

$$
A D_{1} \cdot V_{1}=A D_{2} \cdot V_{2}
$$

where $\mathrm{AD}_{1}$ and $\mathrm{AD}_{2}$ are active drag in both trials, $V_{1}$ corresponds to the speed of the swimmer without the added load $\left(\mathrm{m} . \mathrm{s}^{-1}\right)$, and $V_{2}$ represents the speed of the swimmer with the added load $\left(\mathrm{m} . \mathrm{s}^{-1}\right)$. VPM assumes that average drag relates to speed squared (Eq. 6):

$$
A D=K \cdot V^{2}=\frac{1}{2} \rho \cdot S \cdot C_{d} \cdot V^{2}(6)
$$

where $\rho$ is the density of the water $\left(1000 \mathrm{~kg} \cdot \mathrm{m}^{-3}\right), S$ is the cross-sectional area of the swimmer $\left(\mathrm{m}^{2}\right), C_{d}$ is a dimensionless drag coefficient, and $\mathrm{K}$ is a constant of proportionality $\left(\mathrm{N} \cdot \mathrm{s}^{2} \cdot \mathrm{m}^{-2}\right)$. Combining Eqs. (5) and (6) leads to (Eq. 7):

4

$$
\frac{1}{2} \rho \cdot S \cdot C_{d} \cdot V_{1}^{3}=\frac{1}{2} \rho \cdot S \cdot C_{d} \cdot V_{2}^{3}+F_{b} \cdot V_{2}(7)
$$

where $F_{b}$ is the added resistance due to the HB (Newtons). Active drag can finally be calculated according to (Eq. 8):

$$
A D_{1}=\frac{F_{b} \cdot V_{2 .} V_{1}^{2}}{V_{1}^{3}-V_{2}^{3}}
$$

To prevent inaccuracies in drag measurement, a load controlled outside of the water is preferable, which can be achieved thanks to the ADES (Bideau et al., 2003; Nicolas et al., 2007). In this approach, the swimmer is linked via a non-elastic wire to the device on the side of the pool. Moreover, the swimmer wears a belt placed around the hip joint, which also gives the opportunity of recording the pelvic girdle's speed. During his performance, the swimmer unrolls a spool placed in the device. The spool's rotation can be braked by adjusting a button that applies on the swimmer a load ranging from a few Newtons to $100 \mathrm{~N}$. This system allows measuring the velocity of the swimmer at a sampling rate of $200 \mathrm{~Hz}$. 
$V_{1}$ and $V_{2}$ (Eq. 8) are calculated from digitized sequence, as the mean horizontal velocity of the center of mass (COM) after body digitization, during three stroke cycles, and for each $25 \mathrm{~m}$ trial. COM was computed from standard anthropometric tables (Dempster, Gabel, \& Felts, 1959). In order to compute the segment mass/total mass fraction of each body segment, it was assumed that most of the extra mass of the monofin was added to the center of mass of the foot, following the methodology from Zamparo et al. (2002; Zamparo, Pendergast, Termin et al., 2005).

At speeds close to $3 \mathrm{~m} / \mathrm{s}$, we adjusted in this experiment a load of $F_{b}=20 \mathrm{~N}$. AD is then obtained for the first trial (without load) at maximum speed, as a mean value computed from 3 stroke cycles. Furthermore, as VPM is sensitive to velocity measurement, we also analyzed the reproducibility of active drag values by reiterating this latter protocol the day after, with a new load of $F_{b}=25 \mathrm{~N}$. All presented results only include monofin swimmers for which small variations between both AD measurements were less than $5 \%$. If some fin-swimmers had generated higher AD value of more than $10 \%$ (which implies the conservation of power output hypothesis may have been violated (Toussaint et al., 2004)), they were therefore rejected from the study.

\subsection{Cross-sectional area}

In order to gain further insights into the hydrodynamics involved, the projected frontal area $S$ was computed using planimetry technique (Clarys, 1979; Toussaint et al., 1988). By definition, the monofin swimming motion is undulatory, and hence $S$ is expected to change during the stroke cycle. In this study, multiple measurements were realized in order to compute cross-sectional areas (denoted $S_{i}$ ) for some key events in the stroke cycle (e.g., upstroke, downstroke, transitions up/downstroke and down/upstroke) (see Fig. 3). To this end, two calibration frames of known area (close to the swimmers path) were used: one located at $10 \mathrm{~m}$ and one located at $15 \mathrm{~m}$ from the initial impulse wall. From these two calibrations frames, two reference areas could be calculated. Other intermediate reference areas were linearly interpolated between the two reference frames and enabled to determine the corresponding frontal areas $S_{i}$ associated to the key postures selected during the stroke cycle. In this experiment, the area enclosed by the body of 
the swimmer was hand digitized using a computer-based image analysis software application (Scion Image 4.0.3.2 for Windows; ScionCorporation, USA).

************************************Fig. 3 near here $* * * * * * * * * * * * * * * * * * * * * * * * * * * * * * *$

Fig. 3. Selected postures during an underwater swimming cycle.

In this approach, $S$ refers to the highest $S_{i}$ computed during the swimming cycle. Indeed $S_{\max }$ is supposed to be associated with the highest vertical amplitude (which corresponds to upward and/or downward phase) (Nicolas et al., 2007).

By rearranging Eq. (6), it is possible to compute the drag coefficient $C_{d}$, using the value of $S$ previously calculated, and AD provided by Eq. (8). This provides the following equation (Eq. 9):

$$
C d=\frac{A D}{\frac{1}{2} \rho \cdot S \cdot V_{1}^{2}}=\frac{F b \cdot V_{2}}{\frac{1}{2} \rho \cdot S \cdot\left(V_{1}^{3}-V_{2}^{3}\right)} \text { (9) }
$$

\subsection{Statistics}

A paired $t$-test has been used to detect any statistical difference for the two swimming conditions (underwater vs. surface swimming). In some cases, partial correlation (denoted $r_{x, y / z}$ ) was used in order to describe the relationship between two variables $x$ and $y$ whilst taking away the effects of another variable $z$ on this relationship. A significant statistical difference is observed if $p<.05$.

\section{Results}

Table 2 presents comparison between kinematic parameters for underwater and surface swimming. Results show significant lower velocities during surface swimming vs. underwater $\left(\overline{\mathrm{V}_{1, \text { under }}}=\right.$ $2.5 \mathrm{~m} \cdot \mathrm{s}^{-1}$ vs. $\overline{\mathrm{V}_{1, \text { surf }}}=2.36 \mathrm{~m} \cdot \mathrm{s}^{-1}, t=21.3, d f=11, p<.01$ ). For both displacements (underwater or surface), velocity corresponded to less than one body length per second $\left(\overline{\mathrm{V}_{1, \text { under }} / \mathrm{L}_{\mathrm{b}}}=.90 \mathrm{vs} . \overline{\mathrm{V}_{1, \text { surf }} / \mathrm{L}_{\mathrm{b}}}\right.$ 
$1=.85)$. Velocities during underwater and surface swimming are strongly correlated $(r=.97, p<.01)$. No correlation was found between velocity and body length, whatever the kind of trial.

$* * * * * * * * * * * * * * * * * * * * * * * * * * * * * * * * * * *$ Table 2 near here $* * * * * * * * * * * * * * * * * * * * * * * * * * * * * * *$

Table 2. Kinematic parameters and Froude efficiency for each subject $(\mathrm{n}=12)(\mathrm{SD}$ means standard deviation, $\mathrm{CV}$ means coefficient of variation).

$0.55 \mathrm{~m}$ vs. $\left.\overline{\mathrm{A}_{\text {surf }}}=0.46 \mathrm{~m}, t=11.6, d f=11, p<.01\right)$. Relative amplitude was significantly larger for underwater swimming $(p<.01)$, but remained relatively constant for underwater $\left(\mathrm{A}_{\text {under }} / \mathrm{L}_{\mathrm{b}}=0.20 \pm 0.03\right)$ and surface swimming $\left(\mathrm{A}_{\text {surf }} / \mathrm{L}_{\mathrm{b}}=0.17 \pm 0.03\right)$ (Fig. 4). Kick frequency was also slightly higher during surface swimming $\left(\overline{\mathrm{f}_{\text {under }}}=2.08 \mathrm{~Hz}\right.$ vs. $\left.\overline{\mathrm{f}_{\text {surf }}}=2.15 \mathrm{~Hz}, t=-2.6, d f=11, p<.01\right)$.

$* * * * * * * * * * * * * * * * * * * * * * * * * * * * * * * * * * \mathrm{Fig}, 4$ near here $* * * * * * * * * * * * * * * * * * * * * * * * * * * * * * *$

Fig. 4. Length-specific amplitude, $A / L$, as a function of length-specific swimming speed, $V_{1} / L_{b}$. Mean values of length-specific amplitude for underwater and surface swimming conditions are respectively indicated in solid and dotted lines. amplitude and frequency on velocity for both trials.

No correlation was observed between frequency and $\mathrm{V}_{1} / \mathrm{L}_{\mathrm{b}}$ in both conditions (underwater vs. surface).

For underwater swimming, the product $A . f$ is correlated to speed $(r=-.67, p<.05)$. A partial correlation analysis showed that whereas speed is weakly correlated to amplitude when the effect of $f$ is controlled $\left(R_{V . A f f}=-.53, p<.05\right)$, it was more strongly correlated to frequency while holding $A$ constant $\left(R_{V f f / A}=-.68, p<.05\right)$. 
In contrast, the product A. $f$ was less correlated to speed for surface swimming $(r=-.57, p<.05)$. Nevertheless, a partial correlation analysis also showed that, whereas speed was weakly correlated to amplitude when the effect of $f$ is controlled $\left(R_{V . A f f}=-.59, p<.05\right)$, it was more strongly correlated to frequency while holding $A$ constant $\left(R_{V \cdot f / A}=-.73, p<.05\right)$.

Because of the possible technical adaptations for surface or underwater swimming, swimming efficiencies were also compared. Table 3 shows that efficiency for surface swimming was about $6 \%$ lower than for underwater swimming $\left(\overline{\eta_{\mathrm{F}, \text { under }}}=.79\right.$ vs. $\left.\overline{\eta_{\mathrm{F}, \text { surf }}}=.74 ; t=8.7, \mathrm{df}=11, p<.01\right)$. This means that less energy was "wasted" by imparting kinetic energy to water during underwater swimming.

Table 3 presents dynamic parameters obtained for surface and underwater swimming. Active drag during surface swimming was about $7 \%$ higher than for underwater swimming $\left(\overline{\mathrm{AD}_{\text {under }}}=78.9 \mathrm{~N}\right.$ vs. $\left.\overline{\mathrm{AD}_{\text {surf }}}=84.7 \mathrm{~N} ; \mathrm{t}=-9.7, d f=11, p<.01\right) . \mathrm{AD}$ was strongly correlated with cross-sectional area for underwater $(r=.88, p<.01)$ and for surface swimming $(r=.82, p<.01)$.

$* * * * * * * * * * * * * * * * * * * * * * * * * * * * * * * * * * *$ Table 3 near here $* * * * * * * * * * * * * * * * * * * * * * * * * * * * * * *$

Table 3. Efficiency and drag parameters for each subject $(\mathrm{n}=12)(\mathrm{SD}$ means standard deviation, $\mathrm{CV}$ means coefficient of variation).

$\mathrm{AD}$ at $\left.\mathrm{V}=1 \mathrm{~m} \cdot \mathrm{s}^{-1}\right)\left(\overline{\mathrm{K}_{\text {under }}}=12.7\right.$ vs. $\left.\overline{\mathrm{K}_{\text {surf }}}=15.4 ; t=-18.3, d f=11, p<.01\right)$. This global parameter included a significantly lower cross-sectional area for surface swimming $\left(\overline{\mathrm{S}_{\text {under }}}=0.053 \mathrm{~m}^{2}\right.$ vs. $\overline{\mathrm{S}_{\text {surf }}}=$ $\left.0.044 \mathrm{~m}^{2} ; t=10.1, d f=11, p<.01\right)$, but higher drag coefficient for surface swimming $\left(\overline{\mathrm{C}_{\mathrm{d} \text {,under }}}=.47 \mathrm{vs}\right.$. $\left.\overline{\mathrm{C}_{\mathrm{d}, \text { surf }}}=.69 ; \mathrm{t}=-15.6, d f=11, p<.01\right)$.

Cross-sectional area was significantly associated with vertical amplitude of the fin for underwater swimming $(r=.77, p<.01)$ and for surface swimming $(r=.85, p<.01)$ (Fig. 5). 


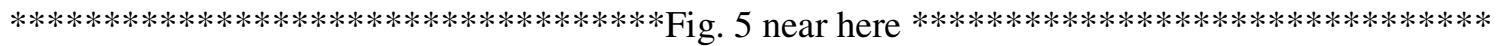

Fig. 5. Cross-sectional area vs. vertical amplitude of the fin for surface and underwater displacement.

\section{Discussion}

The goal of this article was to define and compare the adjustments for high level monofin swimmers during surface and underwater displacement at maximum speed. This comparison aimed at describing the specific adjustments for surface displacement due to the free surface.

As expected, results showed significant lower velocities (6\% decrease) during surface swimming vs. underwater, which is in accordance with World Records differences presented in Table 1 . Whereas a specific velocity can reach values close to 3 (3 body lengths covered per second) for cetaceans, this parameter is relatively constant and close to 0.9 for underwater and surface monofin swimming in humans. By re-analyzing the data provided by Clothier (2004), values close to 0.7 can be estimated for swimmers in (unaided) dolphin kick, which proves a substantial propulsion benefit when using monofin.

Our results revealed a strong relationship between underwater and surface velocities which could therefore be attributed to the differentiating variable, i.e., swimming depth (or air-water interface). This hypothesis may be discussed from several viewpoints.

In both monofin swimming and swimming, technical skill can be analyzed through various kinematic parameters (such as speed, amplitude, or frequency) or through dynamic parameters (such as active drag).

From a kinematic point of view, the undulatory technique during surface swimming induces significant reductions of vertical amplitude of fin oscillation (16\% reduction, $p<.01$ ), as shown in previous works (Szilagyi et al., 1999). Relative amplitudes are in the order of $20 \%$ during underwater swimming, which is close to the value usually reported for fish and cetaceans (Baindbrige, 1958; Ungerechts et al., 1998). However, no data based on the body length with outstretched arms are yet reported for swimmers using the dolphin kick. Significantly lower relative amplitudes for surface swimming (17\%) were reported, which points out that the surface of the water reduces the freedom of 
motion at the ankle joint. Whatever the kind of displacement, a relatively narrow range of relative amplitudes is performed by monofin swimmers and cetaceans. These findings suggest optimal undulatory kick amplitudes may exist for the production of maximal undulatory swimming velocity.

At the same time, kick frequency was also slightly but significantly higher for surface swimming. However, given that swimming speed is different in the two cases, the differences in kick frequency should be larger at paired speed when swimming on the surface and underwater. Spontaneous maximum frequency is therefore affected with free surface, but not in a large magnitude. This range remains also close to values obtained for dolphin kick in regular swimming (Arellano et al., 2002; Clothier, 2004). Despite an enlarged propulsive area due to the monofin, frequency is not affected much and may therefore be more dependent on intrinsic coordination characteristics. Indeed, preserving a high maximum frequency is an invariant of maximum velocity (Arellano et al., 2002; Nicolas et al., 2007). However, the effect of increased propulsive area on kinematics has not yet been totally examined. In contrast, fish generally keep the amplitude of the tail almost constant and increase speed by increasing the frequency of the beat (Baindbrige, 1958). This is not the case for monofin swimmers: no correlation between frequency and $\mathrm{V}_{1} / \mathrm{L}_{\mathrm{b}}$ in both conditions (underwater vs. surface) was measured, contrary to the common trend observed for fish (Bainbridge, 1958). Nevertheless, the limited range of speed, which was considered maximal in this study, could explain this result. For a larger range of speeds (lower speeds), correlation (lower frequency) may be expected.

More generally, the adjustment of kick frequency with rather constant amplitude may engender low distortion of the body, and therefore decreases active drag and increase efficiency. To verify this hypothesis and gain more insights into the hydrodynamics of underwater and surface swimming, crosssectional area $(\mathrm{S})$ and drag coefficient $\left(\mathrm{C}_{\mathrm{d}}\right)$ were computed. To our knowledge, no study reported $\mathrm{S}$ and $\mathrm{C}_{\mathrm{d}}$ at maximal speed for monofin swimmers. We therefore chose to compare $S$ and $C_{d}$ values to those presented in Toussaint et al. (1988) for front crawl at a maximal speeds close to $2 \mathrm{~m} / \mathrm{s}$ as it is based on a close planimetry technique. Even if speeds are clearly higher in monofin swimming than in front-crawl swimming $\left(\bar{V}=2.5 \mathrm{~m} \cdot \mathrm{s}^{-1}\right.$ vs. $\left.2 \mathrm{~m} \cdot \mathrm{s}^{-1}\right)$, the undulatory technique induces a reduction of the cross-sectional area $\left(\bar{S}_{\text {surface }}=0.044 \mathrm{~m}^{2}\right.$ vs. $\bar{S}_{\text {crawl }} \approx 0.09 \mathrm{~m}^{2}$, measured with a close method $)$ and drag coefficient $\left(\mathrm{C}_{\mathrm{d}}=.47\right.$ 
vs. $\left.C_{d}=.64\right)$ (Toussaint et al., 1988). Significant lower cross-sectional areas were calculated for surface vs. underwater swimming, which was related to a reduction of vertical amplitude for this kind of trial (see Fig. 5). Indeed, the undulatory motion is based only on simultaneous vertically oriented motions of the fin, which can be quantified by the amplitude of oscillation (Ungerechts, 1983). This parameter combined with the fin geometry (large trapezoid surface) implies a relatively simple cross-sectional shape during the undulatory motion. This is not the case in regular strokes (e.g., front crawl) for which all four limbs are involved and interact in complex trajectories.

Cross-sectional area directly influences active drag (see Eq. 6). In our study, AD values are based on Velocity Perturbation Method (Kolmogorov \& Duplisheva, 1992). Because of the possible effect of pelvic girdle's vertical oscillations on velocity measurement (Psycharakis \& Sanders, 2008), we did not use pelvic girdle's speed provided with ADES, but used velocities obtained from digitized sequences. The adjustable load $\left(F_{b}\right)$ was chosen in order to avoid AD area close from singularity (when $V_{1}=V_{2}$ ), which usually result in a high sensitivity for $\mathrm{AD}$ measurement. As a consequence, with $\mathrm{F}_{\mathrm{b}}=20 \mathrm{~N}$, each swimmer never decreased the velocity $\mathrm{V}_{2}$ for more than $10 \%$, compared to $\mathrm{V}_{1}$, as recommended by Kolmogorov and Duplisheva (1992). Underwater AD values $\left(\overline{\mathrm{AD}_{\text {under }}}=78.9 \mathrm{~N}\right)$ are about $7 \%$ lower to those found for surface swimming $\left(\overline{\mathrm{AD}_{\text {surf }}}=84.7 \mathrm{~N}\right)(p<.01)$, which is in accordance with results obtained for towed swimmers at similar speeds (Lyttle et al., 1998). However, comparison to previous works is difficult as the only study that reported active drag values during undulatory swimming was based on a net force measurement (Lyttle et al., 2000). To reduce cross-sectional area and therefore (form) drag, a good streamlining is advised which involves minimizing excessive vertical (and lateral) movements. However, whereas a large amplitude is shown to provide a greater kicking velocity than reduced amplitude kicks (Clothier, 2004), the amplitude remains in a proportion of body length usually close to 20\%. This proportion may therefore ensure a good compromise between increasing velocity and reducing active dag. To confirm this hypothesis, it may be interesting to test the effect of various fin amplitudes on kinematic and dynamic parameters. 
Drag coefficient $\left(\mathrm{C}_{\mathrm{d}}\right)$ was significantly higher for surface swimming $(p<.01)\left(\overline{\mathrm{C}_{\mathrm{d} \text {,under }}}=.47 \mathrm{vs}\right.$.

$2 \overline{\mathrm{C}_{\mathrm{d} \text {,surf }}}=.69$ ), despite the reduced amplitude observed for this kind of trial. This result could therefore be $10<.01)$.

attributed to the free surface effect, and more specifically to the wave drag component. Several previous studies indeed showed a significant decrease of the drag coefficient with swimming depth for towed swimmers, and more variability due to the drag bumps (Vennell et al., 2006). For active swimming, an increase in drag coefficient by a factor of up to 5 was reported, depending on the ratio of depth to body diameter, and on the swimming speed (Weihs, 2004). As a result, it can be observed that in the constant of proportionality $K=0.5 \rho S C_{d}$, drag coefficient has the greatest influence for surface swimming. Therefore, this constant $\mathrm{K}$ is significantly higher for surface swimming than for underwater swimming ( $p$

Kinematic and dynamic results suggest different stroke techniques for the two displacements, which may potentially influence Froude efficiency. Our results showed Froude efficiency values in the same order $\left(\eta_{\mathrm{F}}=.7-.8\right)$ as previous studies (Nicolas et al., 2007; Zamparo, Pendergast, Termin et al., 2005). However, no studies quantified the effect of surface vs. underwater swimming on efficiency. Results showed that Froude efficiency for surface swimming is about $6 \%$ lower than for underwater swimming, which may be due to the free surface. Previous studies showed that Froude efficiency is largely affected by kick frequency (Nicolas et al., 2007; Zamparo et al., 2002; Zamparo, Pendergast, Termin et al., 2005). Indeed, from Eq. 4, an increase of wave speed (associated to an increase of $f$ ) leads to a decrease in $\eta_{\mathrm{F}}$, ceteris paribus (Zamparo, Pendergast, Termin et al., 2005). Our study showed that swimming frequency is slightly but significantly higher for surface swimming compared to underwater swimming. Wave component may therefore have an impact on kick frequency, and may therefore prevent from reaching high values of $\eta_{\mathrm{F}}$ for surface swimming. Another hypothesis may come from the reduced opportunity to exploit the recovery stroke during surface swimming.

Whatever the swimming condition (underwater or surface swimming), the dependency of $\eta_{\mathrm{F}}$ with $f$ associated with the preferred correlation of horizontal speed with $f$ (rather than A) seems to suggest that the variable on which swimmers can operate to improve performance is indeed the movement frequency 
1 (Nicolas et al., 2007). $f$ may therefore be adjusted in order to satisfy the energy requirements as a function

2 of race distances. Ideally, the ability to swim faster arises from the capacity (1) to produce a high

3 mechanical power output enabling the generation of high propulsive forces; (2) to reduce drag, and (3) to

4 perform at a high efficiency (Toussaint \& Truijens, 2005). Our results demonstrate that fastest fin-

5 swimmers respect these fundamental principles. Nevertheless, the capacity to maintain a high velocity (for

6 longer distance) appeals more to the aerobic system, and requires good economy. Given the predominant

7 contribution of anaerobic work at maximal speeds, economy was not taken into account in our study. In

8 this latter case, being able to realize a high power output is indeed more important as being economical.

9 More generally, in order to improve the technique of monofin swimmers, several points may be

10 mentioned. First, when compared to regular swimming, it could be theorized that the forward stretched

11 arm increases the length of the hull, with consequent reduction of the wave drag (Toussaint et al., 2002).

12 Also, the extended arms could reduce the pressure above it and in front of the head, thereby reducing the

13 amplitude of the bow-wave, i.e., similar to function of the cone shaped nose below the water-line in large

14 ships (van Oossanen \& Oosterveld, 1989). The evaluation of the wave component in monofin swimming

15 may therefore be an attractive and important issue in order to provide new technical recommendations.

16 Whereas the "non-stationarity" of the hull of the swimmer (technique) has an effect on wave drag for

17 regular swimming, the hull remains globally constant during monofin swimming and may facilitate the interpretation of the results.

Another solution to reduce total drag in surface swimming is to evade wave drag by swimming substantially below the water surface after start-dive and turns. In our approach, the swimming depth was standardized at $1 \mathrm{~m}$, which enables to limit the impact of the wave component. However, we cannot ensure the depth was totally optimal for these monofin swimmers. One important aspect for future works should be to define this optimal depth for high level monofin swimmers. Nevertheless, it should also be reminded that high level swimming does not aim only at reducing drag. For underwater phases, a clever compromise between wave drag decrease (linked to swimming depth) and the time taken to reach this swimming depth has to be found. Future works should also take these two parameters into account. 


\section{References}

Abdel-Aziz, Y. I., \& Karara, M. H. (1971). Direct linear transform from comparator coordinates into object space coordinates in close-range photogrammetry. In Proceedings of the American Society of Photogrammetry (pp. 1-19). Champaign-Urbana, Ill.: University of Illinois at Champaign-Urbana.

Alexander, R. M. (1977). Swimming. In R. M. Alexander \& G. Goldspink (Eds.), Mechanics and energetics of animal locomotion (pp. 222-249). London: Chapman \& Hall.

Arellano, R., Pardillo, S., \& Gavilán, A. (2002). Underwater undulatory swimming: Kinematic characteristics, vortex generation and application during the start, turn and swimming strokes. Applied Proceedings of the XXth International Symposium on Biomechanics in Sports - Swimming.

Bainbridge, R. (1958). The speed of swimming of fish as related to size and to frequency and amplitude of the tailbeat. Journal of Experimental Biology, 35, 109-133.

Bideau, B., Colobert, B., Nicolas, G., Le Guerroué G., Multon, F., \& Delamarche, P. (2003). Development of an active Drag Evaluation System (A.D.E.S.). In J. C. Chatard (Ed.), Biomechanics and medicine in swimming IX (pp. 51-56). Publications de l'Université de Saint Etienne, France.

Clarys, J. P. (1979). Human morphology and hydrodynamics. In J. Terauds, \& E. W. Bedingfield (Eds.), International Series on Sport Sciences - Swimming III (pp. 3-43). University Park Press.

Clothier, P. J. (2004). Underwater kicking following the freestyle tumble turn. Ph.D. Dissertation, University of Ballarat, Australia.

Dempster, W. T., Gabel, W. C., \& Felts, W. J. L. (1959). The anthropometry of manual work space for the seated subject. American Journal of Physiology and Anthropometry, 17, 289-317.

Gautier, J., Baly, B., Zanone, P. G., \& Watier, B. (2004). A kinematic study of finswimming at surface. Journal of Sports Science and Medicine, 3, 91-95.

Kolmogorov, S., \& Duplisheva, O. (1992). Active drag, useful mechanical power output and hydrodynamic force coefficient in different swimming strokes at maximal velocity. Journal of Biomechanics, 25, 311-318. 
Lighthill, M. J. (1975). Mathematical biofluiddynamics. Philadelphia: Society for Industrial and Applied Mathematics.

Luk T. C., Hong Y., Chu P. K., \& Li, S. (1999). Kinematic characteristics of lower extremity during 50m breathhold of fin swimming. In Scientific Proceedings of the XVII International Symposium on Biomechanics in Sports, Perth, Western Australia (pp. 77-80).

Lyttle, A. D., Blanksby, B. A., Elliott, B. C., \& Lloyd, D. G. (1998). The effect of depth and velocity on drag during the streamlined glide. Journal of Swimming Research, 13, 15-22.

Lyttle, A. D., Blanksby, B. A., Elliott, B. C., \& Lloyd, D. G. (2000). Net forces during tethered simulation of underwater streamlined gliding and kicking techniques of the freestyle turn. Journal of Sport Sciences, 18, 801-807.

Nicolas, G., Bideau, B., Colobert, B., \& Berton, E. (2007). How are Strouhal number, drag, and efficiency adjusted in high level underwater monofin swimming? Human Movement Science, 26, 426-442.

Psycharakis, S. G., \& Sanders, R. H. (2008). Validity of the use of a fixed point for intracycle velocity calculations in swimming. Journal of Science and Medicine in Sport. In press. doi:10.1016/j.jsams.2007.11.008

Rejman, M. (1999). Dynamic criteria for description of single fin technique. In K. L. Keskinen, P. V. Komi, \& A. P. Hollander (Eds.), Biomechanics and medicine in swimming VIII (pp. 171-176). Jyväskylä: Gummerus Printing House.

Rejman, M., \& Borowska, G. (2008). Searching for criteria in evaluating the monofin swimming turn from the perspective of coaching and improving technique. Journal of Sports Science and Medicine, 7, 67-77.

Szilagyi, T., Kocsis, L., Thukral, R., Lelovics, Z., \& Barabas, A. (1999). Kinematic analysis of surface and underwater fin-swimming. In R. Sanders \& J. Listen (Eds.), Scientific Proceedings of the XVII International Symposium on Biomechanics in Sports, (pp. 73 -76). Edith Coman University, Perth, Western Australia. 
Toussaint, H. M., de Groot, G., Savelberg, H. H. C. M., Vervoorn, K., Hollander, A. P., \& van Ingen Schenau, G. J. (1988). Active drag related to velocity in male and female swimmers. Journal of Biomechanics, 21, 435-438.

Toussaint, H. M., van Stralen, M., \& Stevens, E. (2002). Wave drag in front crawl swimming. In K. Gianikellis (Ed.), XXth International Symposium on Biomechanics in Sports (pp. 279-282). Casceres: University of Extremadura.

Toussaint, H., Roos, P. E., \& Kolmogorov, S. (2004). The determination of drag in front crawl swimming. Journal of Biomechanics, 37, 1655-1663.

Toussaint, H. M. \& Truijens, M. J. (2005). Biomechanical aspects of peak performance in human swimming. Animal Biology 55, 17-40.

Ungerechts, B. E. (1983). A comparison of the movements of the rear parts of dolphins and butterfly swimmers. In A. P. Hollander, P. A. Huijing, \& G. de Groot (Eds.), International series of sport science (pp. 215-221.). Champaign, Ill., USA. Human Kinetic Publishers.

Ungerechts, B. E., Daly, D., \& Zhu, J. P. (1998). What dolphins tell us about hydrodynamics. Journal of Swimming Research, 13, 1-7.

van Oossanen, P, Oosterveld, M.W.C. (1989). Hydrodynamic resistance characteristics of humans, dolphins and ship forms. Schiffstechnik, 36, 31-48.

Vennell, R., Pease, B., \& Wilson, B. (2006). Wave drag on human swimmers. Journal of Biomechanics, 39, 664-671.

Vogel, S. (1994). Life in moving fluids: The physical biology of flow (2nd ed.). Princeton: Princeton University Press.

von Loebbecke, A., Mittal, R., Fish, F., \& Mark, R. (2009). A comparison of the kinematics of the dolphin kick in humans and cetaceans. Human Movement Science, 28, 99-112.

Weihs, D. (2004). The hydrodynamics of dolphin drafting. Journal of Biology, 3, article 8.

Zamparo, P., Capelli, C., Cautero, M., \& Di Nino, A. (2000). Energy cost of front-crawl swimming at supra-maximal speeds and underwater torque in young swimmers. European Journal of Applied Physiology, 83, 487-491. 
1 Zamparo, P., Pendergast, D. R., Termin, B., \& Minetti, A. E. (2002). How fins affect the economy and efficiency of human swimming. Journal of Experimental Biology, 205, 2665-2676.

Zamparo, P., Pendergast, D. R., Mollendorf, J., Termin, B., \& Minetti, A. E. (2005). An energy balance of front crawl. European Journal of Applied Physiology, 94, 134-144.

Zamparo, P., Pendergast, D. R., Termin, B., \& Minetti, A. E. (2005). Economy and efficiency of swimming at the surface with fins of different size and stiffness. European Journal of Applied Physiology, 96, 459-470. 
Fig.1

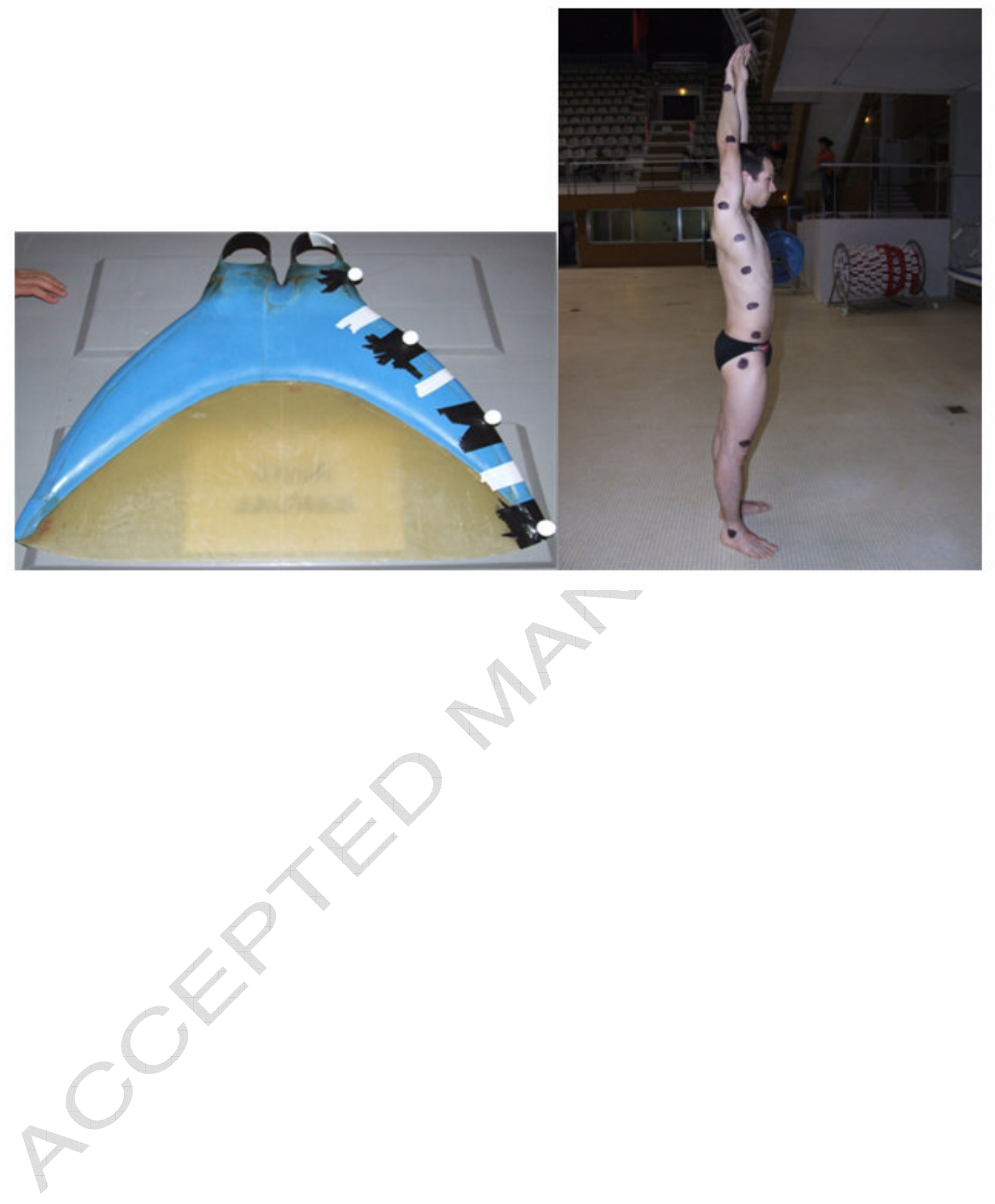


Fig.2

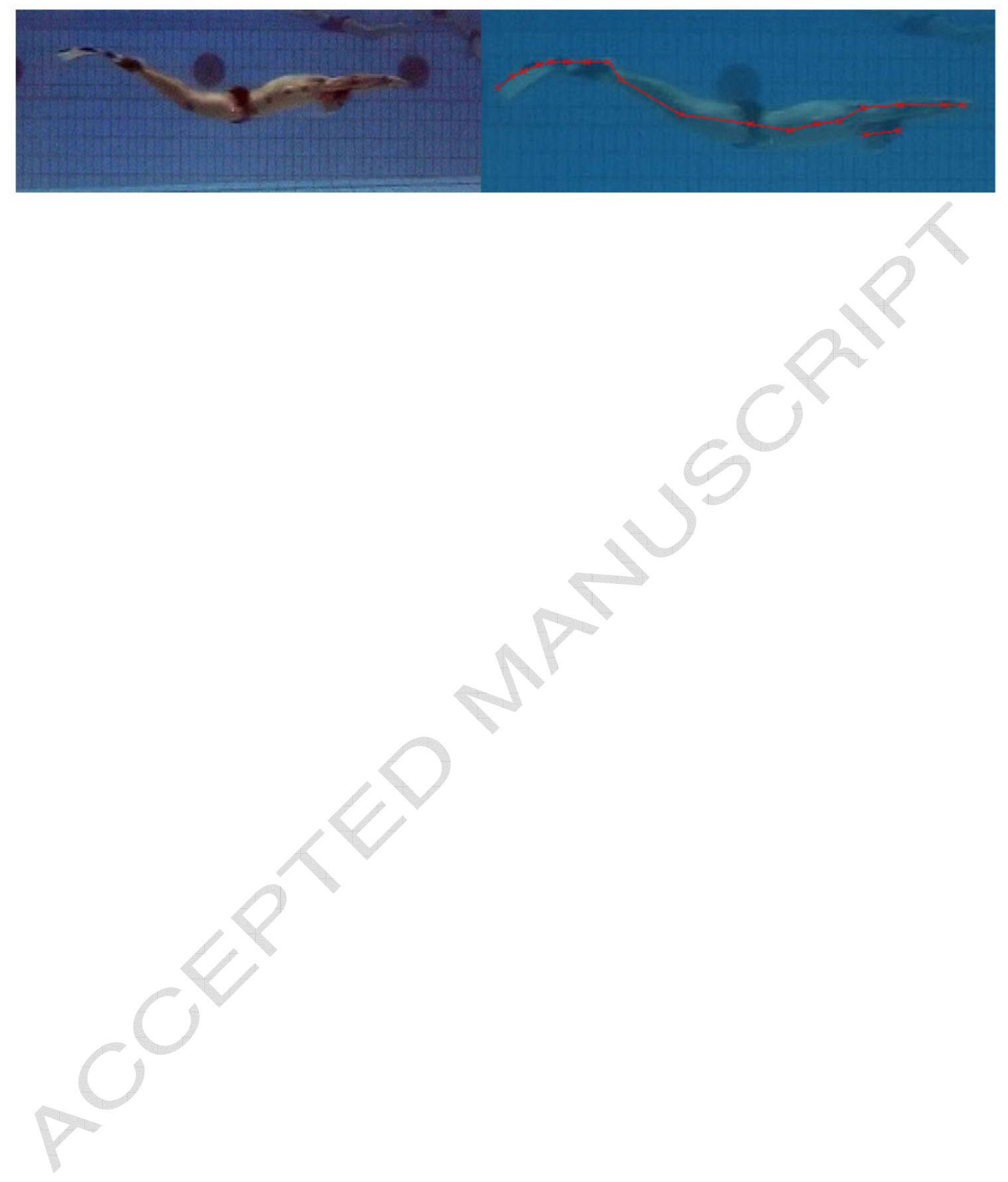


Fig.3

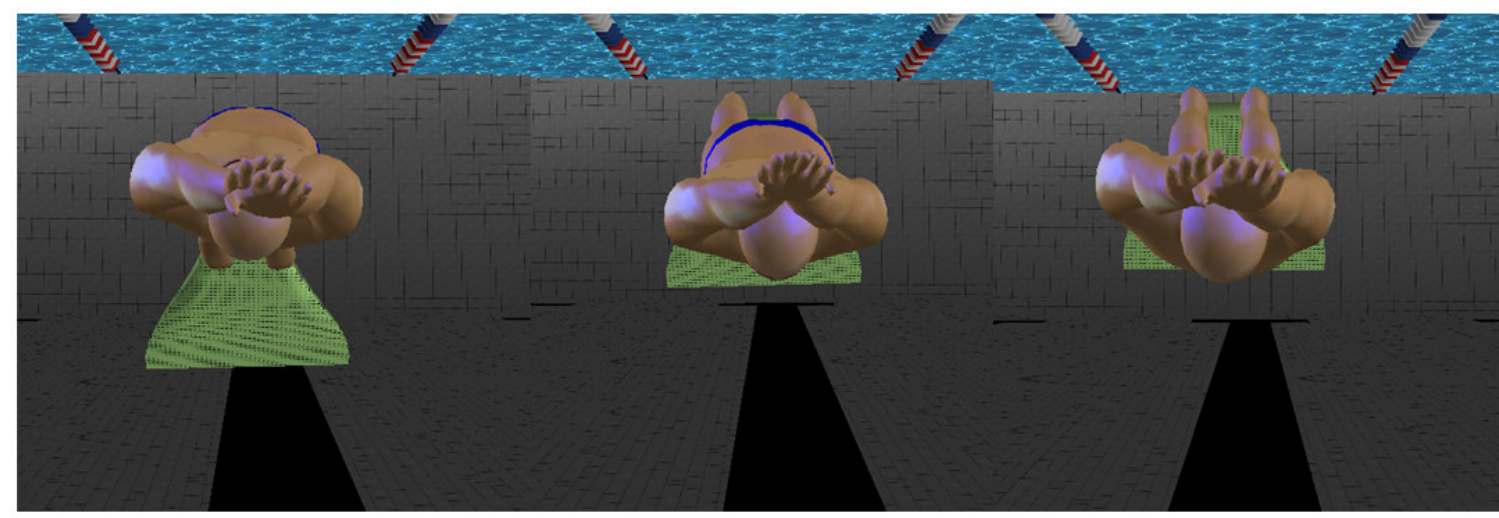


Fig.4

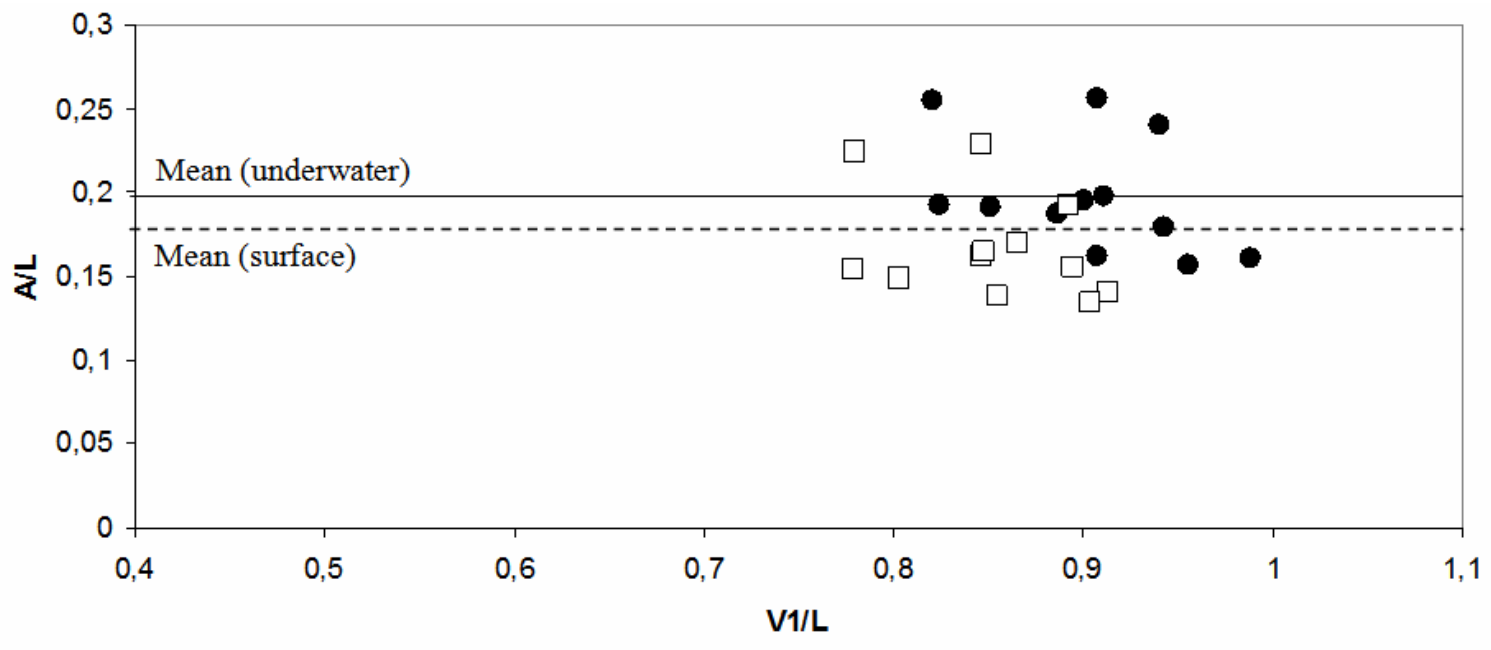

- Underwater swimming $\square$ Surface swimming 
Fig.5

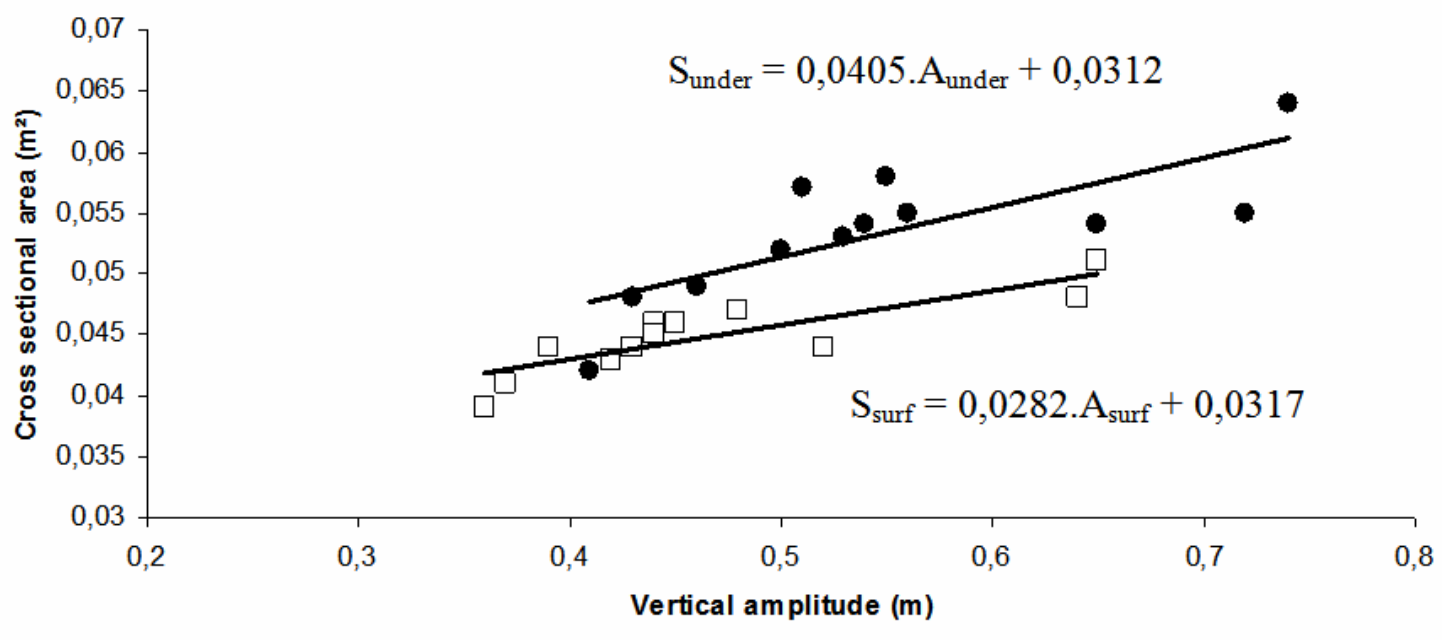

$\bullet$ underwater swimming $\square$ surface swimming 
Table. 1

\begin{tabular}{cccc}
\hline Male & Surface & Immersion & $\begin{array}{c}\text { Difference (\%) } \\
\text { surf vs imm }\end{array}$ \\
\hline 50 & $15^{\prime \prime} 20$ & $14^{\prime \prime} 17$ & $6.8 \%$ \\
100 & $34^{\prime \prime} 79$ & $31^{\prime \prime} 52$ & $9.4 \%$ \\
200 & $1^{\prime} 22^{\prime \prime} 35$ & & \\
400 & $2^{\prime} 59^{\prime \prime} 74$ & $2^{\prime} 46^{\prime \prime} 41$ & $7.4 \%$ \\
800 & $6^{\prime} 23^{\prime \prime} 96$ & $5^{\prime} 52^{\prime \prime} 72$ & $8.1 \%$ \\
1500 & $12^{\prime} 27^{\prime \prime} 15$ & & \\
\hline Female & & & $10.5 \%$ \\
\hline 50 & $17^{\prime \prime} 40$ & $15^{\prime \prime} 57$ & $10.6 \%$ \\
100 & $38^{\prime \prime} 96$ & $34^{\prime \prime} 82$ & $10.3 \%$ \\
400 & $1^{\prime} 30 " 34$ & & $7.4 \%$ \\
800 & $3^{\prime} 17^{\prime \prime} 36$ & $2^{\prime} 57^{\prime \prime} 06$ & \\
1500 & $6^{\prime} 54^{\prime \prime} 30$ & $6^{\prime} 23 " 61$ & \\
\hline
\end{tabular}




\section{Table. 2}

\begin{tabular}{|c|c|c|c|c|c|c|c|c|c|c|c|c|c|c|}
\hline Subject & H (m) & $\begin{array}{c}\text { Body } \\
\text { mass } \\
\text { (kg) }\end{array}$ & $\mathrm{L}_{\mathrm{b}}(\mathrm{m})$ & $\begin{array}{l}V_{1, \text { under }} \\
\left(\mathbf{m} \cdot \mathbf{s}^{-1}\right)\end{array}$ & $\begin{array}{l}V_{1, \text { surf }} \\
\left(\mathrm{m} \cdot \mathrm{s}^{-1}\right)\end{array}$ & $\begin{array}{c}\% \Delta V \\
(\%)\end{array}$ & $\begin{array}{c}\mathrm{V}_{\mathrm{l}}, \\
\text { under } / \\
\mathrm{L}_{\mathrm{b}}\end{array}$ & $\begin{array}{c}\mathrm{V}_{\mathrm{l}, \text { surf }} \\
/ \mathbf{L}_{\mathrm{b}}\end{array}$ & $\begin{array}{c}A_{\text {under }} \\
\text { (Im) }\end{array}$ & $\begin{array}{c}A_{\text {surf }} \\
\text { (Im) }\end{array}$ & $\mathbf{A}_{\text {under }} / \mathbf{L}_{\mathbf{b}}$ & $\begin{array}{c}\mathbf{A}_{\text {surf }} \\
/ \mathbf{L}_{\mathbf{b}}\end{array}$ & $\begin{array}{c}\mathbf{f}_{\text {under }} \\
(\mathbf{H z})\end{array}$ & $\begin{array}{r}\mathbf{f}_{\text {surface }} \\
(\mathbf{H z})\end{array}$ \\
\hline 1 & 1,82 & 75 & 2,83 & 2,58 & 2,45 & 5 & 0,91 & 0,87 & 0,56 & 0,48 & 0,20 & 0,17 & 1,88 & 1,98 \\
\hline 2 & 1,77 & 73 & 2,81 & 2,55 & 2,38 & 6.6 & 0,91 & 0,85 & 0,72 & 0,64 & 0,26 & 0,23 & 1,79 & 1,87 \\
\hline 3 & 1,83 & 76 & 2,85 & 2,35 & 2,22 & 5.5 & 0,82 & 0,78 & 0,55 & 0,44 & 0,19 & 0,15 & 2,94 & 2,76 \\
\hline 4 & 1,66 & 60 & 2,55 & 2,52 & 2,33 & 7.5 & 0,99 & 0,91 & 0,41 & 0,36 & 0,16 & 0,14 & 2,17 & 2,25 \\
\hline 5 & 1,75 & 69 & 2,78 & 2,62 & 2,49 & 5 & 0,94 & 0,90 & 0,5 & 0,43 & 0,18 & 0,15 & 1,97 & 1,99 \\
\hline 6 & 1,71 & 65 & 2,70 & 2,54 & 2,41 & 5.1 & 0,94 & 0,89 & 0,65 & 0,52 & 0,24 & 0,19 & 2,01 & 2,11 \\
\hline 7 & 1,71 & 63 & 2,72 & 2,45 & 2,30 & 6 & 0,90 & 0,85 & 0,53 & 0,44 & 0,19 & 0,16 & 2,03 & 2,18 \\
\hline 8 & 1,8 & 72 & 2,82 & 2,4 & 2,26 & 5.6 & 0,85 & 0,80 & 0,54 & 0,42 & 0,19 & 0,15 & 2,40 & 2,41 \\
\hline 9 & 1,84 & 77 & 2,83 & 2,57 & 2,42 & 5.8 & 0,91 & 0,85 & 0,46 & 0,39 & 0,16 & 0,14 & 1,94 & 2,02 \\
\hline 10 & 1,71 & 66 & 2,73 & 2,42 & 2,31 & 4.3 & 0,89 & 0,85 & 0,51 & 0,45 & 0,19 & 0,16 & 1,93 & 2,03 \\
\hline 11 & 1,75 & 68 & 2,75 & 2,63 & 2,48 & 5.5 & 0,96 & 0,90 & 0,43 & 0,37 & 0,16 & 0,13 & 2,06 & 2,23 \\
\hline 12 & 1,93 & 85 & 2,90 & 2,38 & 2,26 & 5 & 0,82 & 0,78 & 0,74 & 0,65 & 0,26 & 0,22 & 1,85 & 1,97 \\
\hline Mean & 1,77 & 71 & 2,77 & 2,50 & 2,36 & 5.6 & 0,90 & 0,85 & 0,55 & 0,46 & 0,20 & 0,17 & 2,08 & 2,15 \\
\hline S.D. & 0,07 & 7 & 0,09 & 0,10 & 0,09 & 0,8 & 0,05 & 0,05 & 0,10 & 0,09 & 0,03 & 0,03 & 0,31 & 0,24 \\
\hline C.V. $(\%)$ & 3.9 & 10 & 3,3 & 3.8 & 3.9 & 15.3 & 5,7 & 5,4 & 19 & 20.3 & 17,6 & 18,7 & 15,1 & 11,4 \\
\hline
\end{tabular}


Table. 3

\begin{tabular}{|c|c|c|c|c|c|c|c|c|c|c|}
\hline Subject & $\eta_{F \text {,under }}$ & $\eta_{F, \text { surf }}$ & $\begin{array}{c}\mathbf{A} \mathbf{D}_{\text {under }} \\
\text { (N) }\end{array}$ & $\mathbf{A} \mathbf{D}_{\text {surf }}(\mathbf{N})$ & $\begin{array}{c}\mathbf{K}_{\text {under }} \\
\left(\mathrm{N} \cdot \mathrm{s}^{2} \cdot \mathbf{m}^{-2}\right)\end{array}$ & $\begin{array}{c}\mathbf{K}_{\text {surf }} \\
\left(\mathbf{N}^{2} \cdot \mathbf{s}^{2} \cdot \mathbf{m}^{-2}\right)\end{array}$ & $\begin{array}{c}S_{\text {under }} \\
\left(\mathbf{m}^{2}\right)\end{array}$ & $\begin{array}{l}\mathbf{S}_{\text {surf }} \\
\left(\mathbf{m}^{2}\right)\end{array}$ & $\mathbf{C}_{\mathrm{d} \text {, under }}$ & $\mathbf{C}_{\mathrm{d}, \text { surf }}$ \\
\hline 1 & 0,82 & 0,76 & 74.6 & 85.1 & 11.2 & 14.2 & 0.055 & 0.047 & 0.41 & 0.60 \\
\hline 2 & 0,79 & 0,75 & 87 & 91.4 & 13.4 & 16.1 & 0.055 & 0.048 & 0.49 & 0.70 \\
\hline 3 & 0,71 & 0,67 & 94.8 & 101.2 & 17.2 & 20.5 & 0.058 & 0.046 & 0.59 & 0.89 \\
\hline 4 & 0,79 & 0,77 & 59.7 & 64.7 & 9.4 & 11.9 & 0.042 & 0.039 & 0.45 & 0.64 \\
\hline 5 & 0,82 & 0,78 & 69.6 & 74.4 & 10.1 & 12 & 0.052 & 0.044 & 0.39 & 0.55 \\
\hline 6 & 0,8 & 0,74 & 86.6 & 91.3 & 13.2 & 15.7 & 0.054 & 0.044 & 0.49 & 0.77 \\
\hline 7 & 0,8 & 0,78 & 77.6 & 82 & 12.9 & 15.5 & 0.053 & 0.045 & 0.48 & 0.69 \\
\hline 8 & 0,75 & 0,71 & 79.8 & 83.1 & 13.8 & 16.3 & 0.054 & 0.043 & 0.52 & 0.76 \\
\hline 9 & 0,81 & 0,73 & 68.3 & 75.8 & 10.3 & 12.9 & 0.049 & 0.044 & 0.42 & 0.59 \\
\hline 10 & 0,81 & 0,75 & 76.6 & 82.2 & 13.1 & 15.4 & 0.057 & 0.046 & 0.46 & 0.63 \\
\hline 11 & 0,81 & 0,78 & 72.8 & 77.6 & 10.5 & 12.6 & 0.048 & 0.041 & 0.44 & 0.62 \\
\hline 12 & 0,75 & 0,69 & 99.1 & 107.9 & 17.4 & 21.1 & 0.064 & 0.051 & 0.55 & 0.83 \\
\hline Mean & 0,79 & 0,74 & 78.9 & 84.7 & 12.7 & 15.4 & 0.053 & 0.045 & 0.47 & 0.69 \\
\hline S.D. & 0,03 & 0,04 & 11.3 & 11.9 & 2.61 & 3 & 0.005 & 0.003 & 0.058 & 0.10 \\
\hline C.V. (\%) & 4.3 & 4.9 & 14.4 & 14.01 & 20.54 & 19.6 & 10.3 & 7.0 & 12.4 & 15.2 \\
\hline
\end{tabular}

